\title{
Is Psychiatry Scientific? A Letter to a 21st Century Psychiatry Resident
}

\author{
Jose de Leon ${ }^{1,2} \bowtie$ \\ ${ }^{1}$ University of Kentucky Mental Health Research Center at Eastern State Hospital, Lexington, KY, USA \\ ${ }^{2}$ Psychiatry and Neurosciences Research Group (CTS-549), Institute of Neurosciences, University of Granada, Granada, Spain
}

During the development of the DSM-5, even the lay press questioned psychiatry's scientific validity. This review provides 21 st century psychiatry residents with ways of answering these attacks by defining the concepts and history of psychiatry (a branch of medicine), medicine and science. Psychiatric language has two levels: first, describing symptoms and signs (19th century descriptive psychopathology developed in France and Germany), and second, describing disorders (psychiatric nosology was developed in the early 20th century by Kraepelin and resuscitated by the US neo-Kraepelinian revolution leading to the DSM-III). Science is a complex trial-and-error historical process that can be threatened by those who believe too much in it and disregard its limitations. The most important psychiatric advances, electroconvulsive therapy and major psychopharmacological agents, were discovered by "chance", not by scientific planning. Jaspers's General Psychopathology is a complex 100-year-old book that describes: 1) psychiatric disorders as heterogeneous and 2) psychiatry as a hybrid scientific discipline requiring a combination of understanding (a social science method) and explanation (a natural science method). In the 21st century Berrios reminds us of psychiatry's unfortunate methodological issues due to hybrid symptoms and disorders, some of which are better understood as problems in communication between interacting human beings; in those situations neuroscience methods such as brain imaging make no sense. A new language is needed in psychiatry. East Asian psychiatry residents, who are not particularly attached to the antiquated language currently used, may be particularly equipped for the task of recreating psychiatric language using 21 st century knowledge.

Psychiatry Investig 2013;10:205-217

Key Words Asia; Diagnostic and Statistical Manual of Mental Disorders; Europe; History, 19th century; History, 20th century; History, 21st century; Mental disorders; Psychiatry; United States.

\section{INTRODUCTION}

Dear resident, you know better than this "old man" (my title since my 40s when my son reached his teen years) that we live in a complex cosmopolitan world flooded with Internet data such that a Korean pop star can become a worldwide sensation commanding the attention of millions but perhaps be forgotten just as soon. Cataclysmic economic and cultural changes are happening right before our eyes. European countries are floundering but we do not know how far they will fall, while East Asian countries are ascending but we do not know to what heights they can rise. Meanwhile, psychiatry is

Received: June 13, 2013 Revised: June 14, 2013

Accepted: June 14, 2013 Available online: September 16, 2013

$\triangle$ Correspondence: Jose de Leon, MD

UK Mental Health Research Center at Eastern State Hospital, 1350 Bull Lea Lane, Lexington, KY 40511, USA

Tel: +1-859-246-8440, Fax: +1-859-246-8446, E-mail: jdeleon@uky.edu

(c) This is an Open Access article distributed under the terms of the Creative Commons Attribution Non-Commercial License (http://creativecommons.org/licenses/bync/3.0) which permits unrestricted non-commercial use, distribution, and reproduction in any medium, provided the original work is properly cited. dominated by the United States (US), while European psychiatrists hold on to their memories ${ }^{1}$ as they are unable to contribute original ideas (unlike their predecessors), and East Asian psychiatrists' articles are increasingly influential. ${ }^{2}$

Being a good psychiatrist is a very complex thing, so being raised in a complex world flooded with information is a good thing, but... (there is always a "but" in life) unless you are different from the European and cosmopolitan US residents this "old man" has lectured, your training is seriously flawed. You have 1) no serious understanding of and no "love" for statistics, which is the basis of the scientific approach in medicine, 2) no understanding or interest in the history of the last 2500 years of Western civilization that generated current psychiatric thinking and its flaws, and 3) the tendency to get bored with long, complex readings.

This article places additional information on the more complex issues in tables that can be ignored, but there the interested reader will find some historical context and suggestions for additional reading. Be aware that I am not going to say any more about statistics in the text, since you might imme- 
diately stop reading but, unfortunately, an Italian "dude" in the 16th century called Galileo Galilei originated the scientific method of inquiry after stating that the laws of the universe are essentially mathematical laws. Thus, if you want to be a scientist (besides a psychiatrist) you need to thoroughly understand and systematically use statistics. Since most of you only want to be good psychiatrists and do not aspire to become scientists, I have good news. Living in a rapidly changing world that is becoming extensively computerized is not a threat to your jobs; you will not be able to be replaced by computers because psychiatrists must understand people and have a profound understanding of the language and culture of each of their patients. Computers cannot do that. My two older children want to become physicians. My son has a very high IQ, loves computer games and gets bored with homework. He wants to study medicine and become a neurosurgeon to use his computer gaming and programming skills. His sister, my older daughter, has a brain not well suited for reading but corrected that by reading two books a week for years. She is completely fluent in two languages, has lived in two countries and studied a university major in a third language. Unknown to me, she decided to become a physician and a psychiatrist. She has a bright future as a psychiatrist; she can work in the Americas and in large portions of Europe and Africa. There is no way that she can be replaced by a computer. However, I am not sure about the future of neurosurgery in 25 years; a completely automatic robot may retire my son, at least from his surgeries, before he receives the "blessing" of being called an "old man" by his son.

If you are still with me and agree that we live in a complex, rapidly-changing automated world and want to explore with me whether psychiatry is scientific, you are on a complex ride, since I am attempting to sell you things that your professors in medical school and the attendings in your psychiatry residency have not disclosed to you. They assume that psychiatry is scientific. But after publishing more than 200 articles in PubMed, seeing psychiatric patients for 30 years, and working in two countries as a psychiatrist and researcher, I am nearly convinced that the idea that current psychiatry is scientific may be seriously flawed unless you have a good understanding of science's limitations. This is not an original idea; in the last few years, during which the DSM-5 has been developed by the American Psychiatric Association (APA), there have been major controversies outside and inside US psychiatry. As will be described later, in these times in which "science" is considered the ultimate and only source of truth, people outside of our profession referring to psychiatry as "not scientific" may appear to be fueling the worst possible public relations disaster. The New Yorker is one of the most influential cultural journals in the US. On March 1, 2010,
Menand, a US writer and academic literature professor, wrote an article in The New Yorker entitled "Head Case: Can Psychi-

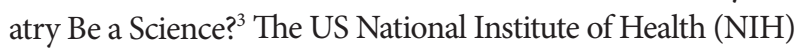
is the research agency of the US federal government for medical research. One of the institutes of the NIH, the National Institute of Mental Health (NIMH), is the most important research institution in the US in psychiatry. In early May 2013, the month that the DSM-5 was officially published, Insel, the NIMH director, wrote a blog post in which he threw the DSM5 into the fire because it "lacks validity", which was reinterpreted by the US press to mean that the DSM-5 is "out of touch with science." The leaders of the APA responded that the new science is not ready to be incorporated into the DSM5 and attempted to repair the marketing damage with a shared statement from the NIMH and the APA. ${ }^{5}$ Having this internal fight aired in US newspapers ${ }^{4}$ and other media has been the latest public failure in the development of a seriously flawed DSM-5.

If you want to determine whether psychiatry is scientific or not, you need to first define what psychiatry is and then define what science is, followed by defining the intersection between them. Unfortunately a third player, medicine, must be brought into this already complex "couple" relationship. In the US, a series of popular books labeled "For Dummies" tries to provide brief, simplified explanations of complex topics for non-experts. Similarly, this article provides brief, simplified versions of topics that are written for psychiatry residents and may be considered as "for dummies" when read by highly critical "experts" on a topic.

\section{WHAT IS PSYCHIATRY?}

To start clarifying whether psychiatry is scientific we must first define psychiatry. It is obvious that psychiatry is a medical specialty. The late Samuel Guze, a US psychiatrist who was chairman at Washington University in St. Louis, wrote an excellent book titled Why Psychiatry is a Branch of Medicine ${ }^{6}$ defending this position. Although the book did not clearly explain it, Guze and his mentor Eli Robins (remember the name) were the leaders of the neo-Kraepelinian movement that rescued psychiatry from the "kidnappers", the psychoanalysts who had dominated US academic psychiatry for 30-40 years. If you are interested in understanding this "ancient history" of psychoanalysis, see Table $1^{7-14}$ to review this kidnapping history.

Next, this section provides simplified histories of psychiatry, medicine, and the first mention of the resistance that a German resident encountered when he tried to introduce scientific thinking to psychiatry 100 years ago. 
Table 1. History of the relationship between psychoanalysis and science

Psychoanalysis and Science

-Development of psychoanalysis. Developed by Freud in Vienna (Austria) during the first years of the 20th century. It is obvious that Freud's original intention was to become a scientist. In 1895, he wrote Project for a Scientific Psychology, ${ }^{7}$ but instead he became a novelist. ${ }^{8}$ This is not an exaggeration; Freud never received the Nobel Prize in Medicine but he received the top German literary award, the Goethe Prize. $^{8}$

-Psychoanalysis is a pseudoscience. Freud's hypotheses cannot be falsified by the scientific method used in the natural sciences; this is why psychoanalysis is one of the best examples of what is called a pseudoscience by thinkers interested in scientific methodology. ${ }^{9}$

-Freud was an expert in marketing and indoctrination. Freud is taught in journalism school as one of the founders of the science of human communication. ${ }^{9}$

Conflating Explanation and Understanding

(read this again after reading Jaspers's General Psychopathology subsection)

-Freud's scientific error. Freud erroneously thought that his hypothetical structural model of the psyche and his theories about arrested psychosexual development (which followed the understanding method) followed the natural sciences model and provided explanations of psychiatric symptoms or even normal human behavior. Thus, Freud erroneously thought that interpreting in psychiatry is like explaining in medicine.

-The unconscious and science. The idea that unconscious thought has great influence on human behavior was not developed by Freud. It was present in many prior thinkers ${ }^{11}$ but Freud, an expert marketer, caused what other people said to be forgotten and, in the process, killed the scientific exploration of this concept for more than 100 years. In the last few years, the concept of unconscious thought is being resuscitated by psychologists using a scientific approach called dual-processing, ${ }^{12}$ but this has not yet reached psychiatry.

Influence of Psychoanalysis on US Psychiatry

-Dominance of psychoanalysis. The emigration of German and Centro-European psychiatrists fleeing from the Nazis brought psychoanalysis to the US in the 1930s and '40s. Psychoanalysis dominated US academic psychiatry until 1980 when the DSM-III was published. ${ }^{13}$ -Defeat of psychoanalysis. In the middle of the dark Freudian era in US psychiatry, a few US psychiatrists (called neo-Kraepelinians), mainly Samuel Guze and his friend and mentor Eli Robins, published a paper with one of their residents, Feighner, as the first author. It unexpectedly changed US psychiatry and led to the DSM-III in 1980. This has been called the neo-Kraepelinian revolution. ${ }^{13,14}$

\section{A history of psychiatry}

I know that you may not like history and think it is irrelevant, but I have bad news for you. All psychiatric concepts and even psychiatric language is seriously contaminated by the vagaries of human history, in this case, mainly French and German history.

Psychiatric language has two interrelated levels (symptom and diagnosis levels). The description of psychiatric symptoms and signs is usually called psychopathology $y^{15,16}$ or, more precisely, descriptive psychopathology ${ }^{17}$ and was developed mainly by French and German psychiatrists. Psychiatry was born in 19th century France and moved to Germany in the second part of the 19th century. ${ }^{18}$ The second level, the organization of symptoms and signs into diagnoses (called nosology), took a major step forward at the beginning of the 20th century in Germany with Kraepelin, who laid the foundation for current psychiatric nosology. ${ }^{19}$ Psychiatric textbooks usually do not place enough emphasis on another major accomplishment in Kraepelin's life; he made the first well-organized attempt to incorporate the neurosciences into psychiatric nosology by developing the German Institute for Psychiatric Research (Table 2). ${ }^{20-25}$ Scientific research is expensive and he had to do marketing; he "only" promised "to cure and prevent mental illness".22

As described above, the NIMH is the leading institution for psychiatric research in the US. Not surprisingly, to compete with others for funding, the NIMH leaders ${ }^{25}$ employed the same marketing promises that Kraepelin used one century before. These NIMH leaders are not only ignoring the failure of Kraepelin's Research Institute but the more recent failure of the pharmaceutical companies. ${ }^{23}$ Unfortunately, serendipitous clinical observation rather than science led to the discovery of all three major classes of psychiatric drugs: antidepressants, antipsychotics, and anxiolytics. Pharmaceutical companies have for 50 years tried to use science to expand the "old" psychiatric drugs and have made a lot of money in the process. However, they are losing their ability to continue making so much money and are running away from psychiatry ${ }^{23}$ because it is too complex and cannot promise a new revenue stream for their stockholders.

\section{A history of medicine}

If psychiatry is a branch of medicine, it may not hurt you to have some understanding of the complex relationship between science and medicine. After three centuries of trying to use the scientific method in medicine, there was a major revolu- 
Table 2. Including neurosciences in psychiatric nosology

First Attempt: Kraepelin's German Institute for Psychiatric Research

-History. It was opened in Munich in 1917. It was a multidisciplinary research institute and initially included laboratories for experimental psychology, neuropathology and chemistry and later on for serology and genealogical demography. ${ }^{19,20}$ Kraepelin died in 1926 . The institute started to crumble in the 1930s due to the interference of Nazi policies and, in 1939, the start of the Second World War made research very difficult. After the war, it was reopened in 1954 as the Max Planck Institute of Psychiatry.

-Kraepelin's collaborators. ${ }^{19,20}$ His collaborators included brilliant scientific minds such as Nissl (famous histopathologist), Alzheimer (neuropathologist), Brodmann (classified cortical areas according to neuron topography), and Rudin (initiated genetic research in psychiatric research).

-Krapelin's marketing: “The foremost task for such a research institute would be to make clear the nature and the sources of mental disturbances, and then to discover ways of preventing them, healing them or making them easier to bear." ${ }^{21}$

Failure to "Cash In" on the Psychopharmacology Lottery*

-Psychopharmacological developments were not based on scientific predictions but were the outcome of serendipity: "The discovery of all three major classes of psychiatric drugs, antidepressants, antipsychotics, and anxiolytics, came about on the basis of serendipitous clinical observation."22

-Scientific developments have made pharmaceutical companies rich by slightly modifying drugs but have provided no major scientific breakthroughs in psychiatric treatment.

-Pharmaceutical companies are abandoning psychiatry due to its complexity. "There are likely additional potentially productive ways to get psychiatric drug research and development back on track but a few things are now clear: 1) what the field has been doing for the past 3 or 4 decades has failed to generate effective, mechanistically novel psychopharmaceuticals, 2) the pharmaceutical industry is now well aware of this fact and has therefore greatly reduced investing, and 3) there is no choice but to make changes in how we approach the study of disease mechanisms, drug discovery, and development in psychiatry. This will require major investments in neuroscience research, humility in the face of our ignorance, and a willingness to consider fundamental reconceptualizations of psychiatry itself. It will be a long, important, and exciting march."22

Current Attempt: US NIMH

-History. The National Institute of Health (NIH) is the main agency of the US federal government for biomedical research, located in Bethesda, Maryland, near Washington, DC. The NIMH is one of 27 institutes and was established in 1947. It focuses on the brain and behavioral sciences to discover the causes of mental disorders and is the largest institution using the neurosciences to resolve the psychiatric "riddle." The NIMH intramural program includes psychiatric research labs and scientists. The NIMH extramural program provides funding for psychiatric research at US universities and other research institutions.

-Current focus. The NIMH has led a progressive abandonment of descriptive psychopathology. In $2010,{ }^{23}$ the NIMH proposed "Research Domain Criteria (RDoC)" as "a new classification framework for research on mental disorders ... incorporating data on pathophysiology ${ }^{\dagger}$ in ways that eventually will help identify new targets for treatment development, detect subgroups for treatment selection, and provide a better match between research findings and clinical decision making."

-Marketing. One hundred years later, NIMH uses marketing similar to that of Kraepelin: "We now have the research tools necessary. Now is the time for research to set an ambitious goal of finding cures and preventive interventions for these disabling illnesses."24

-Problem. The NIMH does not need to report to stockholders; thus it is taking on the impossible task that pharmaceutical companies, which have to report to their stockholders, are abandoning.

${ }^{*}$ In 2011, Fibiger $^{22}$ summarized the position of the pharmaceutical companies regarding psychopharmacological research. ${ }^{\dagger}$ The RDoC framework assumes that data from genetics and clinical neuroscience will yield biosignatures that will augment clinical symptoms and signs for clinical management. Examples where clinically relevant models of circuitry-behavior relationships augur future clinical use include fear/extinction, reward, executive function, and impulse control. ${ }^{23}$

tion in medicine in the 19th century. This revolution was characterized by the convergence of three ways of thinking, which have been called anatomoclinical (relating signs and symptoms with disturbances in specific organs), physiopathological (relating diseases or their symptoms/signs with disturbances in normal physiology) and etiopathological (finding specific causes of some diseases and their lesions). ${ }^{26}$ This led to the revolutionary success of 20th century medicine.
In the opinion of this "old man", Paul McHugh, who was Chairman and Professor of Psychiatry at Johns Hopkins University for approximately 25 years, is one of the few US psychiatrists who will be remembered, due to his acknowledgment of the limitations of US psychiatry in the 20th century. During McHugh's career, US psychiatry moved from a nonscientific approach led by psychoanalysts to a simplistic approach led by psychiatrists believing only in the relevance of 
biology and presenting an overly simplified view of scientific research (see the next section). In one of his last published scientific articles, brief but authoritative, McHugh summarized the problem with US psychiatric nosology and made recommendations. ${ }^{27}$ Even more importantly, McHugh acknowledged that psychiatry was 150 years behind medicine, so we are trying to do what 19th century physicians $\mathrm{did}^{27}$ In the $21 \mathrm{st}$ century psychiatry is pursuing anatomoclinical, physiopathological and etiopathological methods. Unfortunately, we are not being very successful. I think that McHugh would agree our lack of success is related to not paying attention to a book written by a psychiatry resident, Karl Jaspers, 100 years ago.

\section{The history of the ignored resident (Who pays attention to residents anyway?)}

Nissl was an outstanding neuroscientist in the early part of the 20th century. At that time the major development in the neurosciences was in histopathology after Ramon y Cajal proposed the neuron theory (as in other tissue, the nervous system is composed of individual cells called neurons, rather than the reticular theory, its opposite, that the nervous system is a network without separate cells). You know his name because Nissl developed one of the most important staining methods for cell bodies and was one of the major neuropathologists of his day. In 1904, when Kraepelin moved to Munich, Nissl became the Chairman of the Department of Psychiatry at the University of Heidelberg. In 1906, a recently graduated medical student, Karl Jaspers, moved to Heidelberg after his physician recommended it. Jaspers had been diagnosed with bronchiectasis at a time were antibiotics were not available; thus he was not expected to live much longer than his early 30s. His physician recommended "a rigid and restricted working routine that was intended to prolong his life" and got him a job as a trainee (today he would be called a resident) in the Department of Psychiatry. ${ }^{28}$

Jaspers thought that the discipline of psychiatry "was crying out for a systematic clarification of current thinking". 28 Nissl, who was an excellent scientist and an intense, hardworking man, reluctantly agreed to supervise Jaspers's literature review project which later became his thesis. Nissl initially thought Jaspers's project was "philosophical hairsplitting or monkey business." 29

Jaspers had the revolutionary idea that "to make real progress psychiatrists must learn to think". "Jaspers ought to be spanked," replied his contemporaries. ${ }^{28}$ American psychiatrists, except for McHugh, simply ignored this "smarty pants" resident. In defense of Nissl, one has to acknowledge that he later became Jaspers's champion. ${ }^{29}$ In 1913 , when Jaspers was 30 years old, he published his thesis as a book called General Psychopathology. ${ }^{30}$ Jaspers's worry about his health led him to take a position as a lecturer in psychology and later in philosophy. He was married to a Jewish woman (a crime in Nazi Germany) and the train of history derailed his life. ${ }^{28}$ In 1937 he was finally dismissed from the University. He tried unsuccessfully to emigrate from Germany to Switzerland and the US, where Einstein did not help him. When Einstein was asked to recommend Jaspers for his university, Einstein recommended against him since he thought Jaspers's writings looked to him like the "talk of an intoxicated person". ${ }^{30}$ So when you find that you cannot understand Jaspers's writing you can say that you are in the company of Einstein. If you are thinking that you are in good company, be careful; Einstein was unfair to his first wife and completely ignored one of his sons after the son developed schizophrenia.

\section{WHAT IS SCIENCE?}

Trying to explain what science is will require not a book but an encyclopedia, since the definition of science is even more complex and controversial than that of medicine or psychiatry. This section's purposes are to briefly and simply: 1) define science, 2) review its history, and 3) review the history of scientific education in medical training.

\section{A definition of science}

Truthfully, it is not easy to describe what science is or does, which is a difficulty common to all other complex human activities such as art, philosophy or law. It is the reason this "old man" was forced to use as a one-line definition in one of his articles, "Science is a complex trial-and-error historical process led by experts, the scientists," 31 which can easily become a "tautologic" definition when one defines scientists as "the people who practice science".

Table $3^{32-37}$ is an attempt to summarize what science is. First, it describes the limits of science, what it cannot do. Robins, ${ }^{32}$ one of the neo-Kraepelinians, believed that science is incapable of explaining the "important things in life." The issue gets more problematic once one has to acknowledge that science cannot explain itself. ${ }^{32}$ Second, Table 3 provides a lengthy definition of science by Feist, a psychologist who wrote a book on the subject entitled The Psychology of Science and the Origins of Scientific Mind. ${ }^{34}$ This is a highly readable book with almost no statistics.

Third, Table 3 emphasizes the role of scientists and their limitations as subjective human beings no different from other human beings. ${ }^{34,35}$ Fourth, Table 3 explains that science is threatened not only by those who do not believe in science but also by those who believe too much in it and consider it a source of unlimited truth. This is called "scientism." ${ }^{37}$ 
The Limits of Science

-Science cannot explain most important things in life. A physician-scientist $\mathrm{t}^{32}$ who trained with Eli Robins (a US neo-Kraepelinian) said after Robins's death, "My best recollections of that time were late afternoon bull sessions in Eli's office, where we discussed the day's data and many other things. I really didn't appreciate, at the time, how revolutionary Eli's ideas about psychiatry were. His contention that psychiatric illness had an organic basis that was discoverable, and the diagnoses could be made by classical clinical methods, seemed to me at the time obvious and logical. We talked about the differences between the mind and the brain. He made a very important point to me; namely, that despite the power of the scientific method, most of the things in life that are most important to us, such as happiness, love, friendship, fear and compassion, could not be understood or even investigated by any scientific method that we could think of." Please remember that psychiatry many time deals with "these important things in life."

-Science cannot explain itself. Roger Trigg, ${ }^{33}$ a philosopher, discussed this idea in a book entitled Rationality \& Science: Can Science Explain Everything?

Complex Definition

-Feist's definition of science. He explained, "Science involves myriad cognitive and intellectual processes, including abstract and symbolic thought; reasoning and logic; pattern recognition; planning; problem solving; creativity; hypothesis testing; mathematical, analytical, and spatial reasoning; intuitive hunches; chance associations, and the art of coherent and cogent verbal expression and persuasion, to mention but a few of its qualities" ${ }^{34}$

Important Role of Scientists

-Scientists' role according to Feist. "Scientists also think and behave in social contexts; have particular talents and aptitudes; grow up in specific households with particular family structures and influences; have unique personalities that make scientific thought and behavior more rather than less likely; and are motivated by curiosity; intrinsic pleasure of discovery, and the triumph of figuring out how things work." ${ }^{34}$

-Scientists are subjective human beings. Michael Polanyi is known because he stressed that the subjective and personal issues of the scientists exert a powerful influence in scientific advances. ${ }^{35}$

-Scientists are no different from other human beings. Epstein is one of the main psychologists who has tried to use the natural science approach to study the unconscious (dual-process; Table 2) in personality. In his "old age" he wrote this paragraph to summarize his scientific career, "Many moons ago, when the world was young and I was a graduate student in psychology, I believed that psychologists were engaged in a selfless pursuit of truth... To me, it was, at the time, a shocking revelation about the human element in science. I learned that people are people, and being a scientist does not make one more noble in purpose than others. Scientists, like other human beings, are motivated by vested interests, among the more important of which are getting ahead in their field, and relatedly, enhancing their self-esteem and maintaining their belief systems."36

Problems of an Exaggerated Belief in Science

-Scientism. Susan Haack, a philosopher, wrote an excellent book entitled Defending Science Within Reason: Between Scientism and Cynicism. ${ }^{37}$ She defined scientism as, "an exaggerated kind of deference towards science, an excessive readiness to accept as authoritative any claim made by the sciences and to dismiss every kind of criticism of science or its practitioners as anti-scientific prejudice."

\section{A history of science}

Although Feist ${ }^{34}$ wrote an excellent description of the history of science, it is long. In the journal Science, Koshland ${ }^{38}$ provided a very catchy brief description of the history of science which he called "the cha-cha-cha theory of scientific discovery." Koshland ${ }^{38}$ proposed that major advances in science can be explained by a complex mix of 1 ) "charge" (discoveries that solve problems which are quite obvious but the way to solve the problem is not so clear), 2) "challenge" (discoveries that are explained by a new acknowledgment of the limitations of scientific thinking), and 3) "chance" (serendipitous findings made by "prepared minds"). As indicated in Table 2, the history of science in the most important aspects of psychiatry reveals that effective treatments (electroconvulsive therapy and major psychopharmacology agents) were mainly discovered by "chance".

\section{A history of scientific education of physicians}

Michael Polanyi began as a physician, then became an internationally known chemist and finally a philosopher of science (see Table 3 for his views on the influence of personal issues on scientific discoveries). He stressed that the process of learning medicine requires some implicit learning, which is by nature difficult to translate into words and is only learned from the example of a mentor. ${ }^{39}$ Mentoring has been a crucial part of scientific education for physicians in Western civilization for the last 2,500 years. This long history can be briefly summarized as 3 progressive stages ${ }^{31}$ characterized by: 1) mentoring with another physician; 2) the development of European universities that slowly introduced scientific thinking 
in medical education; and 3) in recent years, the idea that evidence-based medicine (EBM) is the answer to our all problems. Around 500 B.C., the Greeks developed the first medical schools and introduced the idea that one learns medicine by rotating with a mentor who teaches the student physician the art of medicine. Then the physician practices by himself and acquires experience as he makes his own mistakes (sometimes lethal to the patients) and, in the case of a few, becomes a physician mentor. This was reflected in what is called the Hippocratic Oath. ${ }^{40}$

In the last half of the 12th century, the first universities were founded in Europe. They began to develop the methodological thinking that made it possible to develop the scientific thinking that flowered with Galileo in the 16th century. The scientific developments in the basic sciences of anatomy and physiology, and later of pathology, were incorporated into medical education, leading to the booming medical sciences in the 19th century and, subsequently, the flourishing of medical applications in the 20th century. In this traditional way of educating physicians found in the first two stages, the older the physician, the more wise and experienced he was supposed to be.

Then some physicians at McMaster University in Canada developed EBM in the 1980s and 1990s. The key physicians were Gordan Guyatt, an internist, and David Sackett, a physician and epidemiologist who contributed to EBM's dissemination by moving to Oxford University. ${ }^{41}$ EBM became a mainstream concept in medicine after the publication of two articles, one in $J A M A^{42}$ in 1992 and one in the British Medical Journal $^{43}$ in 1996. An updated review of EBM was published in $2004 .^{44}$ The EBM approach resulted in an inversion of the traditional process of trusting in older physicians, since older physicians tend to be less experienced with the updates provided by the EBM approach. ${ }^{45}$ From the author's point of view, ${ }^{31} \mathrm{EBM}$ can be seen as the culmination of the introduction of the scientific method in medicine. In the 20th century, the development of the randomized clinical trial (RCT) approach and its progressive adoption by government drug agencies for the purpose of marketing drugs has made the knowledge gained from RCTs available and, more importantly, has led to grouping available RCTs in the so-called meta-analyses, which is the highest level of evidence for EBM. Table 4 indicates that EBM is not free of problems; specifically, EBM is seriously limited by insufficient medical evidence, particularly in psychiatry, and the inadequate skills of physicians as practitioners of EBM. ${ }^{31}$ Feinstein ${ }^{46}$ was a physician with mathematical training, who is usually credited with developing clinical epidemiology. He was very critical of EBM since, in the name of EBM, physicians let experts from the outside reinterpret clinical reality for them. ${ }^{46}$

\section{A review of the pathetic state of science in medicine}

Ioannidis is probably the most influential physician scientist of our day. You are not likely to understand his articles since he loves statistics. He was at the Department of Hygiene and Epidemiology at the University of Ioannina in Greece un-

Table 4. Problems with EBM: a personal view ${ }^{31}$

Medicine-Based Evidence is Limited

The value of EBM is dependent upon medical knowledge of sufficient quantity and quality. If these levels are insufficient, the term "lack of medicine-based evidence" is used. In psychiatry, this insufficiency is particularly severe. The sad truth is that the more difficult the psychiatric patient, due to multiple co-morbidities, the less evidence is available for their treatment.

The Skills of Physicians Are Limited

The author spends a substantial part of his time helping practicing psychiatrists and psychiatry residents with their practical pharmacological problems. This includes considerable effort in teaching them to: 1) use pharmacokinetic and pharmacodynamic knowledge to resolve their therapeutic questions, and 2) employ the EBM approach by using PubMed to search for reviews and meta-analyses. He has had some success in the first task but he has had no success in teaching them basic statistical principles such that they could intelligently assess the typical article published in a psychiatric journal. The author suspects that at McAllister University, Sackett assembled all the physicians interested in statistics, thus draining the US and Canada of them for the next 30-40 years. EBM assumes that the average physician has a sophisticated knowledge of statistics and epidemiology. In a recent review updating the progress of EBM, Guyatt and coworkers ${ }^{44}$ surprisingly gave credit to three people, including Feinstein, for laying the foundations of EBM. This appears quite ironic to the author. You can judge for yourself by reading what Feinstein ${ }^{46}$ wrote of the influence of EBM on physicians, "The average medical doctor who emerges from this process is usually a basically bright person with a mutilated mind. The doctor has seldom been taught or encouraged to establish the credibility of 'facts', to develop or express doubts, to articulate the components that enter into 'judgment', or to question authoritative pronouncements. Instead, either reluctant to use their own minds, or feeling mentally insecure, the doctors try to escape the ardors of thinking: appraisals are delegated to appropriate 'specialists.' The latest approach in the escape process is to delegate appraisals to the specialized meta-analytic results proclaimed as 'evidence-based medicine.' The process is not always successful, however, because the results often differ from medicine-based evidence."

EBM: evidence-based medicine 
til he was hired by Stanford University in San Francisco. He has dedicated his career to demonstrating that many published research findings in medicine are false. ${ }^{47}$ Two major biases can contribute to these false positives: 1) financial and other conflicts of interest, and 2) biases associated with the quest for statistical significance. According to Ioannidis's set of review articles, frequent false positive findings contaminate many areas of medical research, including highly cited clinical research, ${ }^{48}$ epidemiology, ${ }^{49}$ genome-wide association studies, ${ }^{50}$ new technologies called "omics" ${ }^{\text {"51 }}$ and brain volume measures using imaging techniques. ${ }^{52}$ If you think this means that other areas are not contaminated by false findings, the truth may be that Ioannidis has not yet had time to review their articles. In psychiatry, his most important article criticized the antidepressant RCTs. ${ }^{53}$ In the opinion of the author, Feinstein ${ }^{46}$ was correct that it is not a good idea to let experts from the outside reinterpret reality for them, even experts as brilliant as Ioannidis. In this area the author concurs with Bech, ${ }^{54}$ a psychiatrist with remarkable expertise in psychometrics and antidepressant RCTs, who explains that the problem with interpreting antidepressant RCTs is that researchers have been using the Hamilton scale incorrectly in distinguishing antidepressant response from placebo response. This psychometric problem is something that Ioannidis, who has no psychiatric expertise, cannot grasp.

If current medicine is 150 years ahead of psychiatry and is full of false findings, this is not good news for psychiatry, which one might expect to be full of false findings in another 150 years.

\section{THE INTERSECTION OF PSYCHIATRY AND SCIENCE}

\section{Jaspers's General Psychopathology}

Labeling Jaspers as a resident is obviously not historically correct since there were no psychiatry residents one hundred years ago, but it is not far from the truth since he was training in psychiatry after completing medical school. His book General Psychopathology, on scientific methodology in psychiatry, was published in 1913 in German. He later he used this book as a professorial thesis in psychology and left psychiatry completely, so the successive editions were probably updated when Jaspers was no longer seeing patients. The first English translation, more than 900 pages long, was published in 1963 and reflects the 7th German edition..$^{55}$

Unless you are familiar with philosophical readings, do not try to read General Psychopathology, as Einstein indicated, ${ }^{30}$ it may be too complex for you. In the opinion of the author, the book contains two absolutely essential interrelated ideas. First, psychiatric disorders are heterogeneous (some are medi- cal illnesses, some are variations of normality, and others are in the middle, such as schizophrenia and severe mood disorders). Secondly, psychiatry is therefore a hybrid scientific discipline that should combine the methods of the natural sciences (defined as the empirical sciences which study the natural world) and the social sciences. These sciences provide, respectively, an explanation of illness that follows the medical model and an understanding of psychiatric abnormalities that are variations of human living.

You can read McHugh's books for understanding Jaspers's ideas. The heterogeneity of psychiatric disorders is marvelously described in his excellent textbook Perspectives in Psychiatry. ${ }^{57}$ The idea that psychiatry is scientific but with hybrid methods is well-described in a relatively short chapter ${ }^{58}$ of another of McHugh's books called Psychiatric Polarities, which is out of print. It may be easier for you to access one of his articles, ${ }^{59}$ although the chapter ${ }^{58}$ is shorter and easier to read.

The traditional method of the natural sciences used in medicine is called explanation. For example, if you have Alzheimer disease, this can explain psychotic symptoms. The problem is that, for many of the so-called psychiatric disorders, we have no obvious neuropathological or biological findings. Some psychiatric disorders, such as personality disorders, do not fit the medical model or the methods of the natural sciences. To manage psychiatric patients, a psychiatrist must frequently use understanding, a method from the social sciences such as history, and frequently used by writers to write good novels or theatrical plays. Understanding is used to establish whether a belief could be delusional or could be normal in the patient's culture. It is used to establish whether a depressive mood is part of an adjustment disorder, part of a biological illness such as bipolar disorder, or symptomatic of a severe form of major depressive disorder traditionally called melancholia. ${ }^{60}$

\section{Lack of good psychiatric science and the dead end of the DSM-5}

The emigration of German and Centro-European psychiatrists to the US brought psychoanalysis to the US. By the mid1950s nearly every department chairman of psychiatry in the US was an advocate of psychoanalysis. ${ }^{13,14}$ Thus, US training was mostly provided by clinicians not trained in descriptive psychopathology and not interested in psychiatric diagnosis using symptoms; rather, they made psychoanalytic diagnoses by interpreting patient symptoms using psychoanalytic theory.

The neo-Kraepelinians went to war against US academia, which was dominated by psychoanalysis. A turning point in the war was the publication of Feighner's criteria defining 15 psychiatric diagnoses in an operationalized way. ${ }^{14}$ This "heretical" view hit the jackpot by "converting" Spitzer and End- 
icott at the New York Psychiatric Institute (New York was the center of psychoanalytical power). They published the Research Diagnostic Criteria in 1978. ${ }^{61}$ More importantly, Spitzer became the leader in the development of the DSM-III. He outmaneuvered the psychoanalytic establishment ${ }^{13}$ and selected many US psychiatrists contaminated by the neo-Kraepelinian virus to develop the DSM-III criteria. ${ }^{62}$ However, something went wrong in the neo-Krapelinian revolution. ${ }^{63}$ In 1972 with Feighner's criteria, 15 psychiatric disorders appeared to be valid; in 1975 with the Research Diagnostic Criteria, 25 psychiatric disorders appeared to be valid, and in 1980 with the DSM-III, 265 psychiatric disorders appeared to be valid. ${ }^{63}$ So although neo-Krapelinians ${ }^{13,14}$ were originally concerned with the validity of psychiatric disorders, the DSM-III appears to focus mainly on "diagnostic democracy" (agreement among "experts") and interrater reliability. ${ }^{63}$ Thus, in the process of developing the DSM-III, the neo-Kraepelinian concern of psychiatric diagnostic validity was forgotten and Spitzer's idea of improving diagnostic reliability became fundamental. Successive DSM editions have become variants of the same "diagnostic democracy", creating diagnoses through negotiated agreement among so-called experts. ${ }^{63}$

Andreasen was one of the most influential US psychiatrists during the 1980s and 1990s. She was editor of the American Journal of Psychiatry from 1993 to $2006,{ }^{64}$ a major proponent for the introduction of brain imaging in psychiatry ${ }^{65}$ and a leading voice in the US for resurrecting interest in German descriptive psychopathology through her development of schizophrenia symptom scales. ${ }^{66,67}$ In a brave 2007 article, ${ }^{68}$ she pointed out that the "unintended consequence" of the DSM-III was the "death" of the recently resurrected US interest in descriptive psychopathology.

Table 2 describes NIMH's efforts ${ }^{23,24}$ as a repetition of the same empty hope that Kraepelin ${ }^{22}$ expressed 100 years ago: that the neurosciences will save psychiatry. If you are interested in getting a better idea of the thinking behind the approach of the current leaders of the US psychiatric research enterprise, in other words, that the neurosciences can save psychiatry, you may want to read an article by Reynolds et al. ${ }^{69}$ and its critiques. ${ }^{70,71}$

\section{The problem with the current scientific approach in psychiatry: a personal view}

If you ask psychiatric researchers about the challenges of psychiatric research you would probably hear something about the need for more and better technology, but this article proposes a completely different view. This author thinks that the main obstacle to psychiatric advancement is the limitation of psychiatric language. Although this view is called "personal", it is based on ideas that are 100 years old. Descrip- tive psychopathology, the language developed to try to imitate the anatomoclinical approach of the 19th century medical revolution, reached its culmination in 1912 in France and in 1913 in Germany. As previously described, Jaspers, in the culmination of German descriptive psychopathology, warned us of the precarious position of psychiatry between the natural sciences and the social sciences. ${ }^{56}$ This is an extraordinarily weak position if one wants to apply scientific methodology to psychiatric disorders. Since this is very bad news, almost no one has paid attention to this methodological issue for 100 years.

The book reflecting the culmination of French descriptive psychopathology was published in 1912 (one year before Jaspers's book) but it had no impact on English-speaking psychiatry for lack of translation. Chaslin was a seasoned French clinician who, after 25 years of work, published a 956-page book including 350 clinical cases. ${ }^{72}$ Its title can probably be translated as Elements of Mental Semiology and Symptoms. ${ }^{72}$ He also published a superb article in 1914 that has recently been translated into English. ${ }^{73}$ In this article, Chaslin stressed the weakness and lack of accuracy of psychiatric language and offers the unrealistic hope that his textbook would make psychiatry a "well-studied science" with a "well-made language".73 The lack of translation of Chaslin's book to other languages signals two things: 1) the crucial importance of "historical contingencies" in understanding the weakness of nosological systems in psychiatry, ${ }^{74}$ and 2) the difficulty of fulfilling the fantasy that psychiatry can become a science. Unfortunately, both facts appear to be ignored by the current leaders of US psychiatry.

\section{Is there any solution? Yes, but you are not going to like it}

German E. Berrios is the retired Chairman of Epistemology and Psychiatry in the Department of Psychiatry at the University of Cambridge in the United Kingdom. At the beginning of this century Berrios reminded us again of the unfortunate methodological position of psychiatry, dealing with hybrid objects (symptoms and disorders), ${ }^{75}$ some of which fit in the natural sciences and some in the social sciences. The result is different levels of difficulty of study using the traditional scientific methods employed in the natural sciences and in medicine.

The science related to methods of knowing is called epistemology. It can be defined as the science that studies the origins and legitimacy of knowledge. ${ }^{76}$ Berrios's recipe for psychiatry is the "blending of components arising from disparate sources of knowledge ranging from the biological to the semantic in its widest sense." ${ }^{\text {"6 }}$ When the psychiatric symptoms are closely related to brain signals, as in patients with "neurological" disorders, a neuroscience approach and methods such 
as brain imaging make sense, since these symptoms can be explained by a brain disorder. When the psychiatric symptoms are related to semantics and mainly linked to interacting human beings and disturbances in their communication, a natural science approach and methods such as brain imaging make no sense. The symptoms cannot be explained by brain disturbances; rather, they must be understood. These relatively simple concepts are bad news for psychiatric researchers who naturally prefer to ignore them.

The naïve position that using operationalized definitions of psychiatric disorders resolves all methodological issues in psychiatry is compatible with the simplistic way of thinking of current US psychiatry. However, it is not possible to describe psychiatric concepts independently of the systems used to articulate them. ${ }^{77}$ In one of his chapters Berrios comments on the difficulty of developing new elements in psychiatric language, such as new symptoms, because experienced clinicians try to reinterpret them using known psychiatric concepts that are described in 19th century language. ${ }^{78}$

Berrios wrote two key articles, one on the epistemology of psychiatric symptoms ${ }^{79}$ and one on the epistemology of psychiatry, ${ }^{80}$ but the author thinks they may be too complex for a psychiatry resident without training in scientific methodology, and hopes that he doesn't become old and demented before producing shorter and easier versions of these articles for 21st century psychiatry residents.

\section{CONCLUSION}

\section{Unanswered questions}

This "old man" has to acknowledge that he has tricked you. He did not explicitly answer "yes" or "no" to the question, "Is psychiatric scientific?" He is trying to pass along the question to you by providing enough information and additional readings so that you can decide how to answer the question. To be honest, this old man tends to lean to the "no" side; he likes a scientific article written by a psychiatrist and entitled "Psychiatry and the Scientific Fallacy," ${ }^{30}$ as well as a US newspaper column which defines psychiatrists as "heroes of uncertainty." ${ }^{31}$

In complete honesty, "the old man" has to acknowledge that the question should be framed differently. The right question is, "Can current psychiatric knowledge survive the critique of an expert using the methods of the natural sciences?" The answer is "obviously not", but it is fair to clarify that much of our other medical knowledge could not survive such a critique, either. As indicated above, psychiatry is 150 years behind medicine and has the added complexity of dealing with a relatively greater proportion of issues better addressed by the social sciences than the natural sciences.
For the majority of you who will only become medical practitioners in the field of psychiatry and not scientists, the important question is not about science; it is, "How can 21st century psychiatrists better help their patients?" The answer proposed by this "old man" is complex. To start with, as "heroes of uncertainty" ${ }^{\prime 11}$ we must acknowledge the limitations of the language and diagnostic systems we use on behalf of our patients. Then a major dichotomous decision needs to be made. In the first case scenario, the patient has a psychiatric disorder that mainly follows the medical model (e.g., schizophrenia, bipolar disorder or catatonia) where the risk-benefit analysis for biological treatment is reasonably in favor of benefits. Therefore, engage the patient in the best possible biological treatment, according to our limited knowledge and practical availability. As drugs are the major biological treatment available and the psychiatric drugs can be "pretty toxic", you better become an expert in pharmacological science and master the ample scientific knowledge that we have of the pharmacokinetic and pharmacodynamic mechanisms of each of the drugs you prescribe and how to better adjust the drugs to each patient. ${ }^{82}$ In the second case scenario, the patient mainly has a variation of normality and/or a life-story issue. ${ }^{57}$ Consequently, be careful with the use of medications since their effects are small (a meta-analysis would describe small effect sizes when compared with placebo); be very conscientious about double-checking your risk-benefit analysis for prescribing drugs, and do your best to engage the patient in the most suitable educational method, the so-called psychotherapies.

\section{Recapitulation to facilitate learning and a look toward the future}

This article has attempted to provide a brief, simplified, thought-provoking description of very complex topics for interested 21st century psychiatry residents. The scientific validity of psychiatry has been systematically questioned in the US media during the last few years as the DSM-5 was being developed. Is psychiatry scientific? This article tries to provide an answer in case a psychiatry resident needs to defend psychiatry from attacks by lay people who read lay media and documents found on the Internet.

To start determining whether psychiatry is scientific, it is first defined as a medical specialty using a unique language that has two interrelated levels (symptom and diagnosis levels). The description of psychiatric symptoms is usually called descriptive psychopathology and was mainly developed by French and German psychiatrists in the 19th century. The psychiatric symptoms and signs are organized into psychiatric diagnoses. This is called psychiatric nosology. The foundation for psychiatric nosology was laid at the beginning of 
the 20th century by a German psychiatrist named Kraepelin. Kraepelin also led the first organized attempt to incorporate the neurosciences into psychiatry at the German Institute for Psychiatric Research. Current attempts by the NIMH to include the neurosciences in psychiatry are marketing the same empty promises used by Kraepelin 100 years ago. Unfortunately, current US leaders do not acknowledge that psychiatry is 150 years behind medicine and that the task is much more complicated than in medicine. This was described by a German psychiatry resident, Jaspers, in 1913, when he published a textbook called General Psychopathology.

Defining science and what is scientific is even more complex than defining psychiatry or medicine. This is common to all other complex human activities such as art, philosophy or law. Science is a "complex trial-and-error historical process" in which the role of the scientist is crucial. Science cannot explain the "important things in life" and cannot explain itself. Scientists are subjective human beings no different from other human beings and with similar vested interests. Science is threatened not only by those who do not believe in science but also by those who believe too much in it and consider it a source of truth without limitation, which is called "scientism."

A simplified and easy-to-remember theory of scientific discovery (the cha-cha-cha theory) proposed that major advances in science can be explained by a complex mix of 1) "charge" (discoveries solve problems that are quite obvious but the way in which to solve the problem is not so clear), 2) "challenge" (discoveries are explained by a new acknowledgment of the limitations of scientific thinking), and 3) "chance" (serendipitous findings made by "prepared minds"). Unfortunately, the most important aspects of psychiatry, its effective treatments (electroconvulsive therapy and major psychopharmacology agents), were discovered by "chance" rather than scientific planning.

Knowing the role of mentoring is crucial in understanding the history of scientific education for physicians in Western civilization over the last 2,500 years. The history of medical education can be described as three progressive stages: 1 ) mentoring with another physician; 2) the development of Euopean universities, which slowly introduced scientific thinking in medical education; and 3) the reliance in recent years on the idea that EBM is the answer to all our problems. EBM is seriously limited because medical evidence itself is limited, particularly in psychiatry, and because of physicians' limited skills as practitioners of EBM. In turn, these physicians let experts with statistical expertise from the outside reinterpret reality for them. Ioannidis, a physician with statistical training, has demonstrated that many published research findings in medicine are false. If current medicine is 150 years ahead of psychiatry and is full of false findings, this is not good news for psychiatry, which can expect to be full of false findings after another 150 years.

Jaspers's General Psychopathology is a complex book that describes two major interrelated ideas. First, psychiatric disorders are heterogeneous (some are medical illnesses, some are variations of normality, and others are in the middle, such as schizophrenia and severe mood disorders). Secondly, psychiatry is therefore a hybrid scientific discipline that should combine the methods of the natural sciences and the social sciences, which respectively provide an explanation of illness that follows the medical model and an understanding of psychiatric abnormalities that are variations of human living.

The neo-Kraepelinian revolution challenged US academia, which was dominated by psychoanalysis, leading to the DSMIII and its successive editions. Ironically, in the process of developing the DSM-III, the neo-Kraepelinian concern of psychiatric diagnostic validity was forgotten and the idea of improving diagnostic reliability became fundamental. Successive DSM editions have become variants of the same "diagnostic democracy" creating diagnoses through negotiated agreement among so-called experts. The DSM-5 is a dead end, and even the NIMH scientists acknowledge that DSM-5 does not describe valid entities supported by valid scientific research. On the other hand, current scientific findings in the neurosciences cannot be used to develop a valid new psychiatric nosology. It is not clear when that will be possible.

This author thinks that the main problem limiting psychiatric advancement is the antiquated language used in psychiatry. This was emphasized 100 years ago by Jaspers and Chaslin (a French psychiatrist) but has been ignored since it makes psychiatry's scientific methodology very weak. Berrios reminds us again that the unfortunate methodological position of psychiatry, dealing with hybrid objects (symptoms and disorders), ${ }^{75}$ some of which fit in the natural sciences and some in the social sciences. This situation leads to different levels of difficulty of study using the traditional scientific methods employed in natural science and medicine. As a hybrid science, psychiatry must acknowledge symptoms from a range of sources. When psychiatric symptoms are closely related to brain signals, as in patients with "neurological" disorders, a neuroscience approach and methods such as brain imaging make sense, since these symptoms can be explained by a brain disorder. When the psychiatric symptoms are related to semantics and mainly connected to interacting with other people, a natural science approach and methods such as brain imaging make no sense. The symptoms cannot be explained by brain disturbances; rather, they must be understood. These relatively simple concepts are bad news for psychiatric researchers who naturally prefer to ignore them.

East Asian 21st century psychiatry residents may be partic- 
ularly ready for the task of recreating the language of psychiatry (a "challenge", according to the cha-cha-cha theory) since they may not be particularly attached to: 1) the 19th century language of descriptive psychopathology developed in France and Germany, 2) the early 20th century Kraepelin nosology and its failure to incorporate the neurosciences in Germany, or 3 ) the late 20th century US neo-Kraepelinian nosology (DSM-III and later editions) that has led to the dead-end of the DSM-5 and the repetition of Kraepelin's marketing ideas. Pharmaceutical companies no longer believe in the promises of the neurosciences and are leaving the "sinking ship" of psychiatry. The 21 st century psychiatrists cannot do that; they need to take care of their patients as best they can, just as physicians have been "promising" in Western civilization since the Hippocratic oath was developed 2,500 years ago. ${ }^{40}$

\section{Acknowledgments}

The author acknowledges Lorraine Maw, MA, and Margaret T. Susce, RN, MLT, at the Mental Health Research Center at Eastern State Hospital, Lexington, KY, who helped in editing the article.

\section{REFERENCES}

1. de Leon J. The French attempt to include the bouffée délirante in the DSM-V during 2006: a recollection in the year 2050. Encephale 2009; 35:1-3.

2. López-Muñoz F, Shen WW, Pae CU, Moreno R, Rubio G, Molina JD, et al. Trends in scientific literature on atypical antipsychotics in South Korea: a bibliometric study. Psychiatry Investig 2013;10:8-16.

3. Menand L. Head case: can psychiatry be a science? The New Yorker 2010; March 1. http://www.newyorker.com/arts/critics/ atlarge/2010/03/01/100301crat_atlarge_menand. Accessed July 30, 2013.

4. Belluck P, Carey B. Psychiatry's guide is out of touch with science, experts say. New York Times Available at: http://www.nytimes. com/2013/05/07/health/psychiatrys-new-guide-falls-short-expertssay.html?pagewanted=all\&_r=0. Accessed May 6, 2013.

5. Insel T, Lieberman J. DSM-5 and RDoC: shared interests. NIMH press release. Available at: http://www.nimh.nih.gov/news/science-news/2013/ dsm-5-and-rdoc-shared-interests.shtml. Accessed May 13, 2013.

6. Guze S. Why Psychiatry is a Branch of Medicine. New York: Oxford University Press; 1992.

7. Freud S. Project for a Scientific Psychology. In: Stratchey J, Freud A, editors. The Standard Edition of the Complete Psychological Works of Sigmund Freud. London, UK: Hogarth Press, 1955-1974, vol 1, p. 283397.

8. Wortis J. Freud the novelist. Biol Psychiatry 1992;32:1063-1064.

9. Popper K. Conjectures and Refutations. New York: Harper Torchbooks; 1963.

10. Rogers EM. A History of Communication Study: A Biographical Approach. New York: The Free Press; 1997.

11. Ellenberger HF. The Discovery of the Unconscious: The History and Evolution of Dynamic Psychiatry. New York: Basic Books; 1981.

12. Evans JS. Dual-processing accounts of reasoning, judgment, and social cognition. Annu Rev Psychol 2008;59:255-278.

13. Decker HS. How Kraepelinian was Kraepelin? How Kraepelinian are the neo-Kraepelinians?--from Emil Kraepelin to DSM-III. Hist Psychiatry 2007;18:337-360.

14. Kendler KS, Muñoz RA, Murphy G. The development of the Feighner criteria: a historical perspective. Am J Psychiatry 2010;167:134-142.
15. Parnas J, Sass LA, Zahavi D. Rediscovering psychopathology: the epistemology and phenomenology of the psychiatric object. Schizophr Bull 2013;39:270-277.

16. Stanghellini G. The meanings of psychopathology. Curr Opin Psychiatry 2009;22:559-564.

17. Berrios GE. Descriptive psychopathology: conceptual and historical aspects. Psychol Med 1984;14:303-313.

18. Berrios GE. The history of mental symptoms. Cambridge: Cambridge University Press; 1996.

19. Berrios GE, Hauser R. The early development of Kraepelin's ideas on classification: a conceptual history. Psychol Med 1988;18:813-821.

20. Hippius H, Müller N. The work of Emil Kraepelin and his research group in München. Eur Arch Psychiatry Clin Neurosci 2008;258(Suppl 2):3-11.

21. Weber MM. Psychiatric research and science policy in Germany: the history of the Deutsche Forschungsanstalt fur Psychiatrie (German Institute for Psychiatric Research) in Munich from 1917 to 1945). Hist Psychiatry 2000;11:235-258.

22. Kraepelin E. The German institute of psychiatric research. J Nerv Ment Dis 1920;51:505-513.

23. Fibiger HC. Psychiatry, the pharmaceutical industry, and the road to better therapeutics. Schizophr Bull 2012;38:649-650.

24. Insel T, Cuthbert B, Garvey M, Heinssen R, Pine DS, Quinn K, et al. Research domain criteria (RDoC): toward a new classification framework for research on mental disorders. Am J Psychiatry 2010;167:748-751.

25. Insel TR, Scolnick EM. Cure therapeutics and strategic prevention: raising the bar for mental health research. Mol Psychiatry 2006;11:11-17.

26. Lain Entralgo P. Historia de la medicina. Barcelona: Salvat; 1978.

27. McHugh PR. Striving for coherence: psychiatry's efforts over classification. JAMA 2005;293:2526-2528.

28. Kirkbright S. Karl Jaspers: A Biography. Navigations in Truth. New Haven: Yale University Press; 2004.

29. McHugh PR. Genius in a Time, Place and Person: Foreword to Karl Jaspers's General Psychopathology, Volume 1. The Mind Has Mountains: Reflections on Society and Psychiatry. Baltimore: The Johns Hopkins University Press, 2005, p. 147-156.

30. Oliver HH. Karl Jaspers and Modern Physics. In: Ehrlich LH, Wisser R, Editors. Karl Jaspers Today: Philosophy at the Threshold of the Future. Washington, DC: Center for Advanced Research in Phenomenology \& University Press of America, 1988, p.111-131.

31. de Leon J. Evidence-based medicine versus personalized medicine: are they enemies? J Clin Psychopharmacol 2012;32:153-164.

32. Majerus PW. Teacher in the lab. Ann Clin Psychiatry 1995;7:5-6.

33. Trigg R. Rationality and Science: Can Science Explain Everything? Oxford: Blackwell; 1993.

34. Feist GJ. The Psychology of Science and the Origins of the Scientific Mind. New Haven: Yale University Press; 2006.

35. Polanyi M. Personal Knowledge: Towards a Post-Critical Philosophy. Chicago: The University of Chicago Press; 1962.

36. Epstein S. This I have learned from over 40 years of personality research. J Pers 1997;65:3-32.

37. Haack S. Defending Science within Reason. Between Scientism and Cynicism. Amherst, NY: Prometheus Books; 2007.

38. Koshland DE. The cha-cha-cha theory of scientific discovery. Science 2007;317:761-762.

39. Goldman GM. The tacit dimension of clinical judgment. Yale J Biol Med 1990;63:47-61.

40. McHugh PR. Hippocrates à la mode. Nat Med 1996;2:507-509.

41. Cohen L. McMaster's pioneer in evidence-based medicine now spreading his message in England. CMAJ 1996;154:388-390.

42. Evidence-Based Medicine Working Group. Evidence-based medicine: a new approach to teaching the practice of medicine. JAMA 1992;268: 2420-2425.

43. Sackett DL, Rosenberg WM, Gray JA, Haynes RB, Richardson WS. Evidence based medicine: what it is and what it isn't. BMJ 1996;312:71-72. 
44. Guyatt G, Cook D, Haynes B. Evidence based medicine has come a long way. BMJ 2004;329:990-991.

45. Choudry NK, Fletcher RH, Soumerai SB. Systematic review: the relationship between clinical experience and quality of health care. Ann Intern Med 2005;142:260-273.

46. Feinstein AR. What can clinicians contribute to mutual challenges in medical statistics. J Clin Epidemiol 1999;52:365-369.

47. Ioannidis JP. Why most published research findings are false. PLoS Med 2005;2:e124.

48. Ioannidis JP. Contradicted and initially stronger effects in highly cited clinical research. JAMA 2005;294:218-228.

49. Ioannidis JP, Tarone R, McLaughlin JK. The false-positive to false-negative ratio in epidemiologic studies. Epidemiology 2011;22:450-456.

50. Ioannidis JP. Non-replication and inconsistency in the genome-wide association setting. Hum Hered 2007;64:203-213.

51. Ioannidis JP. Expectations, validity, and reality in omics. J Clin Epidemiol 2010;63:945-949.

52. Ioannidis JP. Excess significance bias in the literature on brain volume abnormalities. Arch Gen Psychiatry 2011;68:773-780.

53. Ioannidis JP. Effectiveness of antidepressants: an evidence myth constructed from a thousand randomized trials? Philos Ethics Humanit Med 2008;3:14.

54. Bech P. Is the antidepressive effect of second-generation antidepressants a myth? Psychol Med 2010;40:181-186.

55. Jaspers K. Allgemeine Psychopathologie. Bin Leitfaden fur Studierende, Arzte und Psychologen. 1st Edition. Berlin: Springer; 1913.

56. Jaspers K. General Psychopathology. Translated from the German 7th Edition by Hoenig J and Hamilton MH. Manchester: Manchester University Press; 1963.

57. McHugh P, Slavney PR. The Perspectives of Psychiatry. 2nd Edition. Baltimore: The Johns Hopkins University Press; 1998.

58. Slavney PR, McHugh PR. Explanation and understanding. Psychiatric Polarities. Baltimore: The Johns Hopkins University Press, 1987, p.29-44.

59. McHugh PR, Slavney PR. Methods of reasoning in psychopathology: conflict and resolution. Compr Psychiatry 1982;23:197-215.

60. Parker G, Fink M, Shorter E, Taylor MA, Akiskal H, Berrios G, et al. Issues for DSM-5: whither melancholia? The case for its classification as a distinct mood disorder. Am J Psychiatry 2010;167:745-747.

61. Spitzer RL, Endicott J, Robins E. Research diagnostic criteria: rationale and reliability. Arch Gen Psychiatry 1978;35:773-782.

62. American Psychiatric Association. Diagnostic and Statistical Manual of Mental Disorders, 3rd Edition (DSM-III). Washington, D.C.: American Psychiatric Association; 1980.

63. Dean CE. The death of specificity in psychiatry: cheers or tears? Per- spect Biol Med 2012;55:443-460.

64. Andreasen NC. Farewell, thou child of my right hand. Am J Psychiatry 2006;163:1-2.

65. Andreasen NC. Brain imaging: applications in psychiatry. Science 1988; 239:1381-1388.

66. Andreasen NC. Scale for the Assessment of Negative Symptoms (SANS). Iowa City: University of Iowa; 1983.

67. Andreasen NC. Scale for the Assessment of Positive Symptoms (SAPS). Iowa City: University of Iowa; 1983.

68. Andreasen NC. DSM and the death of phenomenology in America: an example of unintended consequences. Schizophr Bull 2007;33:108-112.

69. Reynolds CF 3rd, Lewis DA, Detre T, Schatzberg AF, Kupfer DJ. The future of psychiatry as clinical neuroscience. Acad Med 2009;84:446450.

70. Sadler JZ. Stigma, conscience, and science in psychiatry: past, present, and future. Acad Med 2009;84:413-417.

71. Healy D, Mangin D. The once and future psychiatry. Acad Med 2009;84: 418-420.

72. Chaslin Ph. Elements de semiologie et clinique mentales. Paris: Asselin et Houzeau; 1912.

73. Berrios GE, Fuentenebro F, Chaslin P. Philippe Chaslin and descriptive psychopathology: is 'psychiatry' a well made language? Hist Psychiatry 1995;6:395-405.

74. Kendler KS. An historical framework for psychiatric nosology. Psychol Med 2009;39:1935-1941.

75. Berríos GE. Psychiatry and its objects. Rev Psiquiatr Salud Ment 2011;4: 179-182.

76. Marková IS, Berrios GE. Epistemology of psychiatry. Psychopathology 2012;45:220-227.

77. Berrios GE. Historiography of mental symptoms and diseases. Hist Psychiatry 1994;5:175-190.

78. Berrios GE, Markova IS. Symptoms-historical perspective and effect on diagnosis. In: Blumenfield M, Strain JJ, Editors. Psychosomatic Medicine. Philadelphia: Lippincott Williams \& Wilkins, 2006, p.27-38.

79. Marková IS, Berrios GE. Epistemology of mental symptoms. Psychopathology 2009;42:343-349.

80. Saraga M, Stiefel F. Psychiatry and the scientific fallacy. Acta Psychiatr Scand 2011;124:70-72.

81. Brooks D. Heroes of uncertainty. New York Times. Available at: http:// www.nytimes.com/2013/05/28/opinion/brooks-heroes-of-uncertainty. html?_r=0. Accessed May 27, 2013.

82. de Leon J. The future (or lack of future) of personalized prescription in psychiatry. Pharmacol Res 2009;59:81-89. 